\title{
PROSPECÇÃO DE SUBSTÂNCIAS BIOATIVAS EM POLPA DE GOIABA MICROENCAPSULADA
}

\author{
O. M. PORCU ${ }^{1}$, D. XAVIER ${ }^{2}$ \\ ${ }^{1}$ Universidade Tecnológica Federal do Paraná - Campus Medianeira, SEBLIC - Química, \\ Docente, Programa Pós Graduação em Processos Químicos e Bioquímicos - Campus Pato Branco \\ ${ }^{2}$ Universidade Tecnológica Federal do Paraná, Departamento de Engenharia Ambiental \\ E-mail para contato: ornellamporcu@gmail.com
}

\begin{abstract}
RESUMO - A goiaba é uma fruta largamente produzida no Brasil e rica em substâncias bioativas que podem reduzir o risco de deficiências nutricionais e doenças crônico degenerativas. Este estudo objetivou o desenvolvimento de um ingrediente funcional e a caracterização da retenção de bioativos na polpa de goiaba (cultivar Paluma) microencapsulada obtida por spray dryer. A produção do microencapsulado de polpa de goiaba (MG) utilizou dextrina como encapsulante. A concentração de fenólicos e flavonoides totais foi determinada e os resultados foram para (MG) 0,72 $\pm 0,03 \mathrm{mg}$ GAE/g e 1,81 $\pm 0,04 \mathrm{mg}$ quercetina/g, respectivamente. O teor de compostos fenólicos totais encontrado foi semelhante à estudos encontrados na literatura. A otimização do processo é necessária para maior retenção dos bioativos.
\end{abstract}

\section{INTRODUÇÃO}

A goiaba (Psidium guajava L) é uma fruta com alto valor no mercado brasileiro, sendo consumida in natura e amplamente utilizada na produção de alimentos industrializados. O Brasil é um dos maiores produtores desta fruta. Entretanto, sua vida útil é curta e seus frutos amadurecem rapidamente, sendo de suma importância o desenvolvimento de produtos industrializados para garantir o consumo desta fruta nos meses de entressafra (Azzolini; Jacomino; Bron, 2004).

Em sua composição, encontram-se grandes quantidades de vitamina $\mathrm{C}$, carotenoides e compostos fenólicos. Estes compostos atuam como antioxidantes, capturando os radicais livres do organismo, apresentando ações anti-inflamatórias, antiplaquetárias, anticancerígenas e hipoglicemiantes (Freire et al., 2012; Haida et al., 2011).

Estas substâncias são facilmente degradadas por fatores ambientais. Alguns processos industriais são aplicados para que se conserve a integridade destes compostos. Um deles é a microencapsulação.

A microencapsulação é o revestimento de uma substância com uma membrana, protegendo-a da oxidação e da decomposição. Pode ser feita através de vários processos e utilizando vários tipos de agentes encapsulantes, sendo cada vez mais aplicada nos processos industriais em vários setores 
(Suave et al., 2006; Santos; Fávaro-Trindade; Grosso, 2005).

Tendo em vista o aproveitamento da goiaba para agregar sabor, aroma e valor nutricional ao produto alimentício proposto para estudo, desenvolveram-se microcápsulas de goiaba através do microencapsulamento por atomização, utilizando como agente encapsulante a dextrina.

O objetivo deste estudo foi obter a goiaba microencapsulada caracterizando a quantidade de substâncias bioativas tais como fenólicos e flavonoides totais após o processo de microencapsulamento.

\section{MATERIAL E MÉTODOS}

Esta pesquisa foi desenvolvida na Universidade Tecnológica Federal do Paraná, Campus Pato Branco, no Laboratório de Bromatologia.

\subsection{Microencapsulação por Atomização (Spray drying)}

Foi utilizado polpa de goiaba fornecido por uma Indústria de Alimentos do estado de Santa Catarina. A variedade da goiaba utilizada foi Paluma, sendo que esta é a mais utilizada industrialmente. A polpa de goiaba foi transportada, embalada em saco plástico revestido de material metálico sob vácuo e mantida congelada a $-10^{\circ} \mathrm{C}$ até o momento de seu uso.

A polpa de goiaba é definida segundo a Instrução Normativa n. 01, de 7 de janeiro de 2000, onde: polpa ou purê de goiaba é o produto não fermentado e não diluído, obtido da parte comestível da goiaba (Psdium guaiajava L.), através de processo tecnológico adequado, com teor mínimo de sólidos totais (Brasil, 2000).

A polpa de goiaba foi submetida a microencapsulação por atomização, utilizando-se dextrina, obtida do amido de mandioca, como agente encapsulante.

Utilizou-se uma proporção de 1:1 de dextrina e polpa de goiaba, obtendo-se na mistura final um teor de sólidos solúveis de $15{ }^{\circ}$ Brix. O preparo da mistura a ser encapsulada consistiu em adicionar $200 \mathrm{~mL}$ de água a $49 \mathrm{~g}$ de dextrina, aquecendo-se a mistura a $80{ }^{\circ} \mathrm{C}$, agitando-se em agitador mecânico de bancada (Fisatam 713D AAKER) a 4800 rpm.min-1 por 3 minutos para que a dextrina se dissolvesse na água. Foi adicionado à mistura anterior, $500 \mathrm{~g}$ de purê de goiaba, voltando à agitação por mais 3 minutos.

Em seguida, a atomização foi conduzida em um Spray Dryer (Lab Maq MSD 1.0), dimensões 
1800 x 500 × $800 \mathrm{~mm}, 160 \mathrm{Kg}$, capacidade máxima de secagem 1 litro por hora. Foi utilizado bico pneumático de 2 fluidos com $1 \mathrm{~mm}$ de abertura e fluxo de ar comprimido para secagem de 45 L.min1. A temperatura de secagem variou de 40 a $60{ }^{\circ} \mathrm{C}$ e a velocidade de secagem de $0,54 \mathrm{~L} . \mathrm{h}^{-1}$.

\subsection{Obtenção dos Extratos}

Para as análises de flavonoides totais e compostos fenólicos totais foi necessário obter um extrato das amostras de goiaba. Assim, a polpa de goiaba (G) e a polpa de goiaba microencapsulada (MG) foram submetidas a extração pela metodologia descrita por Prado (2009).

Foram utilizados solventes etanol:água $(80: 20 \mathrm{v} / \mathrm{v})$. Três gramas da amostra foram transferidas para um erlenmeyer, sendo em seguida adicionados $30 \mathrm{~mL}$ da mistura de solventes. $\mathrm{O}$ erlenmeyer foi submetido à agitação $(200 \mathrm{rpm})$, durante 50 minutos, a temperatura ambiente. Em seguida, os extratos foram centrifugados a $5000 \mathrm{x}$ g durante 15 minutos. Os extratos foram armazenados em geladeira até o momento das análises. Para as análises o extrato bruto foi diluído (1:10).

\subsection{Determinação de Flavonoides Totais}

Para se determinar o conteúdo de flavonoides totais nas amostras de goiaba utilizou-se o método descrito por Park et al. (1995), realizando esta análise em triplicata. Este método baseia-se em uma reação colorimétrica onde $0,5 \mathrm{~mL}$ de cada extrato, foi misturado com 4,3 mL de etanol $80 \%, 0,1 \mathrm{~mL}$ de nitrato de alumínio $10 \%$ e $0,1 \mathrm{~mL}$ de acetato de potássio $1 \mathrm{M}$. Para o controle foi utilizado $0,1 \mathrm{~mL}$ de água destilada no lugar do nitrato de alumínio. Deixou-se em repouso por 40 minutos ao abrigo da luz e mediu-se a absorbância das amostras em espectrofotômetro a $414 \mathrm{~nm}$. A absorbância obtida relaciona o teor de flavonoides totais, com base no padrão de quercetina.

\subsection{Determinação dos Compostos Fenólicos Totais}

O teor de compostos fenólicos totais para as duas amostras de goiaba foi determinado através do método espectrofotométrico de Folin-Ciocalteau, o qual utiliza o ácido gálico como padrão (Singleton; Orthofer; Lamuela, 1999).

A uma alíquota de 0,5 mL do extrato é adicionado 2,5 mL do reagente Folin-Ciocalteau (1:10). Depois de repousar por 5 minutos, foi adicionado a cada tubo $2 \mathrm{~mL}$ de carbonato de sódio $4 \%$, deixou-se em repouso por 2 horas ao abrigo da luz. A leitura foi feita em espectrofotômetro a $740 \mathrm{~nm}$. O branco é feito com água destilada no lugar do extrato. Foi feita uma curva padrão de ácido gálico de 2,5 ppm a 125 ppm, para calibração. A análise foi realizada em triplicata. 


\section{Resultados e Discussões}

Os compostos fenólicos vêm sendo citados como grandes responsáveis pela atividade antioxidante de vegetais e frutas. Os flavonoides são tipos de compostos fenólicos, dentre os quais destacam-se as antocianinas e os flavonóis (Fernandes, 2007).

Os valores dos compostos fenólicos totais equivalentes ao ácido gálico no extrato etanólico, expressos em base seca e dos flavonoides totais obtidos da polpa de goiaba e da polpa de goiaba microencapsulada são apresentados na Tabela 1.

Tabela 1 - Conteúdo Médio de Total de fenólicos e flavonoides de (G) e (MG)

\begin{tabular}{|c|c|c|}
\hline Análise & $\begin{array}{l}\text { Purê de goiaba } \\
\qquad(\mathrm{G})^{(*)}\end{array}$ & $\begin{array}{l}\text { Polpa de Goiaba microencapsulada } \\
\qquad(\mathrm{MG})^{(*)}\end{array}$ \\
\hline 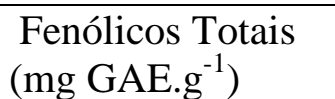 & $1,34^{\mathrm{b}} \pm 0,05$ & $3,29^{\mathrm{a}} \pm 0,08$ \\
\hline $\begin{array}{l}\text { Flavonoides Totais } \\
\left(\mathrm{mg} \mathrm{quercetina.}^{-1}\right)\end{array}$ & $0,72^{b} \pm 0,03$ & $1,81^{\mathrm{a}} \pm 0,04$ \\
\hline
\end{tabular}

${ }^{(*)}$ Letras diferentes na mesma linha indicam diferença significativa $(\mathrm{p}<0,05)$ entre os resultados obtidos para polpa de goiaba $(\mathrm{G})$ e o microencapsulado de polpa de goiaba (MG).

A goiaba em pó obtida do processo de microencapsulação apresentou um teor 2,45 vezes maior de compostos fenólicos totais do que o purê de goiaba.

O teor de compostos fenólicos totais determinados neste estudo foi semelhante aos encontrados por MacCook-Russell et al. (2012), quando determinaram os polifenóis totais em frutas de goiaba e encontraram um valor de 1,95 mg GAE.g ${ }^{-1}$. Além disso, Thaipong et al. (2006) estudou vários genótipos de goiaba e encontrou valores de compostos fenólicos totais de 1,70 à 3,45 mg GAE.g ${ }^{-1}$. Outros estudos encontraram valores superiores, como Prado (2009), que encontrou, na polpa de goiaba fresca, um valor de 5,60 mg GAE.g ${ }^{-1}$ e Freire et al. (2012), que estudando a composição de cultivares de goiaba, apresentou para o cultivar Paluma, um teor de 8,48 mg GAE.g ${ }^{-1}$. Os teores de compostos fenólicos totais podem variar de acordo com vários fatores como, estádios de maturação, condições e localidade de cultivo, cultivares diferentes, condições climáticas, técnicas de análise, entre outros (Oliveira et al., 2011).

Estudos demonstraram que a goiaba possui maior teor de compostos fenólicos totais que muitas outras frutas, entre elas, abacaxi, manga, maracujá, melão e mamão, ficando atrás da pitanga e da acerola (Prado, 2009; Oliveira et al., 2011). Contudo, há trabalhos citando que a casca de goiaba possui maior teor de polifenóis totais que a polpa (Tasca, 2007), além de conter polifenóis totais nas 
folhas de goiaba (Haida et al., 2011).

Quanto ao teor de flavonoides, novamente a goiaba microencapsulada apresentou um valor 2,51 vezes maior do que o purê de goiaba. No purê de goiaba os flavonoides representam cerca de $54 \%$ dos compostos fenólicos totais, enquanto que na goiaba microencapsulada representam cerca de $55 \%$.

Huber e Rodriguez-Amaya (2008) citam que a goiaba vermelha possui $0,02 \mathrm{mg}^{-\mathrm{g}^{-1}} \mathrm{de}$ flavonoides e Pereira (2009) determinou um teor aproximado de $0,08 \mathrm{mg} \cdot \mathrm{g}^{-1}$. Já Hoffmann-Ribani; Rodriguez-Amaya (2008) determinaram um teor de 0,01 mg quercetina. $\mathrm{g}^{-1}$, valores estes citados bem abaixo dos determinados neste estudo para a polpa de goiaba. Entretanto, Tasca (2007), analisando a polpa de goiaba do cultivar Paluma, encontrou valores superiores de flavonoides, de 1,25 à 1,87 mg rutina. $\mathrm{g}^{-1}$.

\section{CONCLUSÃO}

A presença de compostos fenólicos e flavonoides totais se manteve mesmo após a microencapsulação, evidenciando a eficiência da proteção do encapsulamento. Este fato permite propor a utilização do microencapsulado (MG) para a produção de alimentos enriquecidos.

\section{NOMENCLATURA}

$\begin{array}{ll}\mathrm{x} g & \text { Força gravitacional } \\ \mathrm{g} & \text { Grama } \\ { }^{\circ} \mathrm{C} & \text { Grau Celsius } \\ \mathrm{Kg} & \text { Quilograma } \\ \text { L.h-1 } & \text { Litro por hora } \\ \text { L.min-1 } & \text { Litro por minuto } \\ \mathrm{M} & \text { Molar } \\ \mathrm{mg} \mathrm{GAE} . \mathrm{g}-1 & \text { Miligrama de ácido gálico por grama } \\ \mathrm{mg} . \text { g-1 } & \text { Miligrama por grama } \\ \mathrm{ml} & \text { Mililitro } \\ \mathrm{mm} & \text { Milímetro }\end{array}$


$\mathrm{nm}$

Nanômetro

mg quercetina.g-1 Miligrama de quercetina por grama

mg.rutina.g-1 Miligrama de rutina por grama

MG Microencapsulado de polpa de goiaba

ppm parte por milhão

$\% \quad$ Por cento

rpm Rotação por minuto

\section{REFERÊNCIAS}

AZZOLINI, M.; JACOMINO, A. P.; BRON, I. U. Índices para avaliar qualidade pós-colheita de goiabas em diferentes estádios de maturação. Pesq. agropec. bras., Brasília, v. 39, n. 2, 2004.

BRASIL. Instrução Normativa $n^{\circ}$ 01, de 07 de janeiro de 2000. Aprova o Regulamento Técnico Geral para fixação dos Padrões de Identidade e Qualidade para polpa de fruta. Ministério da agricultura e do abastecimento, Brasília, DF, 10 jan. 2000.

FERNANDES, A. G. Alterações das características químicas e físico-químicas do suco de goiaba (Psidium guajava L.) durante o processamento. 2007. 86 f. Dissertação. (Mestrado em Tecnologia de Alimentos) - Universidade Federal do Ceará, Fortaleza, 2007.

FREIRE, J. M.; ABREU, C. M. P.; CORRÊA, A. D.; SIMÃO, A. A.; SANTOS, C. M. dos. Avaliação de compostos funcionais e atividade antioxidante em farinhas de polpa de goiabas. Rev. bras. frutic., Jaboticabal, v. 34, n. 3, 2012.

HAIDA, K. S.; BARON, Â.; HAIDA, K. S.; FACI, D.; HASS, J.; SILVA, F. J. Compostos fenólicos totais e atividade antioxidante de duas variedades de goiaba e arruda. Rev. bras. ciênc. saúde, João Pessoa, n. 9, 2011.

HOFFMANN-RIBANI, R.; RODRIGUEZ-AMAYA, D. B. Otimização de método para determinação de flavonóis e flavonas em frutas por cromatografia líquida de alta eficiência utilizando delineamento estatístico e análise de superfície de resposta. Quím. nova, São Paulo, v. 31, n. 6, 2008.

HUBER, L. S.; RODRIGUEZ-AMAYA, D. B. Flavonóis e flavonas: fontes brasileiras e fatores que influenciam a composição em alimentos. Alim. nutr., Araraquara, v. 19, n. 1, 2008. 
MCCOOK-RUSSELL, K. P.; NAIR, M. G.; FACEY, P. C.; BOWEN-FORBES, C. S. Nutritional and nutraceutical comparison of Jamaican Psidium cattleianum (strawberry guava) and Psidium guajava (common guava) fruits. Food chem., Barking, v. 134, n. 2, 2012.

OLIVEIRA, D. S.; AQUINO, P. P.; RIBEIRO, S. M. R.; PROENÇA, R. P. C.; PINHEIROSANT'ANA, H. M. Vitamina C, carotenoides, fenólicos totais e atividade antioxidante de goiaba, manga e mamão procedente da Ceasa do Estado de Minas Gerais. Acta sci. agron., Maringá, v. 33, n. $1,2011$.

PARK, Y. K.; KOO, M. H.; SATO, H. H.; CONTADO, J. L. Estudo de alguns componentes da própolis coletada por Apis mellifera no Brasil. Arq. biol. tecnol., v. 38, n.4, 1995.

PEREIRA, A. C. S. Qualidade, compostos bioativos e atividade antioxidante total de frutas tropicais e cítricas produzidas no Ceará. 2009. 122 f. Dissertação. (Mestrado em Tecnologia de Alimentos) Departamento de Tecnologia de Alimentos, Universidade Federal do Ceará, Fortaleza, 2009.

PRADO, A. Composição fenólica e atividade antioxidante de frutas tropicais. 2009. $107 \mathrm{f}$. Dissertação. (Mestrado em Ciências) - Escola Superior de Agricultura "Luiz de Queiroz" da Universidade de São Paulo, Piracicaba, 2009.

SANTOS, A. B.; FÁVARO-TRINDADE, C. S.; GROSSO, C. R. F. Preparo e caracterização de microcápsulas de oleoresina de páprica obtidas por atomização. Ciênc. tecnol. aliment., Campinas, v. $25,2005$.

SINGLETON, V. L.; ORTHOFER, R.; LAMUELA, R. M. Analysis of total phenols and other oxidation substrates and antioxidants by means of Folin-Ciocalteau reagent. Meth. Enzymol., v. 299, 1999.

SUAVE, J.; DAlL’AGNOL, E. C.; PEZZIN, A. P. T.; SILVA, D. A. K.; MEIER, M. M.; SOLDI, V. Microencapsulação: Inovação em diferentes áreas. Saúde amb., Joinville, v. 7, n. 2, 2006.

TASCA, A. P. W. Efeito do processamento industrial para obtenção de goiabada sobre os compostos antioxidantes e cor. 2007. 121 f. Dissertação. (Mestrado em Ciência de Alimentos) - Faculdade de Ciências Farmacêuticas, Universidade Estadual Paulista "Júlio de Mesquita Filho", Araraquara, 2007.

THAIPONG, K.; BOONPRAKOB, U.; CROSBY, K.; CISNEROS-ZEVALLOS, L.; BYRNE, D. H. Comparison of ABTS, DPPH, FRAP, and ORAC assays for estimating antioxidant activity from guava fruit extracts. J. food compos. anal., San Diego, v. 19, 2006. 